\title{
BMJ Global Health Economic impacts of overweight and obesity: current and future estimates for eight countries
}

\author{
Adeyemi Okunogbe (D) , ${ }^{1}$ Rachel Nugent, ${ }^{2}$ Garrison Spencer, ${ }^{2}$ Johanna Ralston, ${ }^{3}$ \\ John Wilding ${ }^{3}$
}

To cite: Okunogbe A, Nugent $R$, Spencer G, et al. Economic impacts of overweight and obesity: current and future estimates for eight countries. BMJ Global Health 2021;6:e006351. doi:10.1136/ bmjgh-2021-006351

Handling editor Edwine Barasa

- Additional supplemental material is published online only. To view, please visit the journal online (http://dx.doi.org/10. 1136/bmjgh-2021-006351).

Received 19 May 2021 Accepted 29 August 2021

Check for updates

(C) Author(s) (or their employer(s)) 2021. Re-use permitted under CC BY-NC. No commercial re-use. See rights and permissions. Published by BMJ.

${ }^{1}$ Global Health Division, RTI International, Washington, D.C, USA

${ }^{2}$ Center for Global Noncommunicable Diseases, RTI International, Seattle, Washington, USA

${ }^{3}$ World Obesity Federation, London, UK

Correspondence to Dr Adeyemi Okunogbe; aokunogbe@rti.org

\section{ABSTRACT}

Background Obesity is a growing public health challenge worldwide with significant health and economic impacts. However, much of what is known about the economic impacts of obesity comes from high-income countries and studies are not readily comparable due to methodological differences. Our objective is to demonstrate a method for estimating current and future national economic impacts of obesity and apply it across a sample of heterogeneous contexts globally.

Methods We estimated economic impacts of overweight and obesity for eight countries using a cost-of-illness approach. Direct and indirect costs of obesity from 2019 to 2060 were estimated from a societal perspective as well as the effect of two hypothetical scenarios of obesity prevalence projections. Country-specific data were sourced from published studies and global databases. Results In per capita terms, costs of obesity in 2019 ranged from US\$17 in India to US\$940 in Australia. These economic costs are comparable to $1.8 \%$ of gross domestic product (GDP) on average across the eight countries, ranging from $0.8 \%$ of GDP in India to $2.4 \%$ in Saudi Arabia. By 2060, with no significant changes to the status quo, the economic impacts from obesity are projected to grow to $3.6 \%$ of GDP on average ranging from $2.4 \%$ of GDP in Spain to $4.9 \%$ of GDP in Thailand. Reducing obesity prevalence by $5 \%$ from projected levels or keeping it at 2019 levels will translate into an average annual reduction of $5.2 \%$ and $13.2 \%$ in economic costs, respectively, between 2020 and 2060 across the eight countries. Conclusion Our findings demonstrate that the economic impacts of obesity are substantial across countries, irrespective of economic or geographical context and will increase over time if current trends continue. These findings strongly point to the need for advocacy to increase awareness of the societal impacts of obesity, and for policy actions to address the systemic roots of obesity.

\section{INTRODUCTION}

Between 1975 and 2016, the prevalence of obesity increased in every country in the world. ${ }^{1}$ Overweight and obesity contribute to numerous noncommunicable diseases (NCDs), including cardiovascular disease, diabetes and cancer. ${ }^{2}$ Obesity-related NCDs account for over 5 million deaths globally

\section{Key questions}

What is already known?

- Estimates of the economic impacts of obesity as a percentage of gross domestic product (GDP) range from $0.13 \%$ in Thailand (Pitayatienanan et al) to $9.3 \%$ in the USA (Milken Institute, 2018) with most estimates for high-income countries.

- Most studies use a health system perspective rather than a societal perspective.

- Cost of obesity studies vary considerably in the types of outcomes reported, diseases included for the measurement of healthcare costs, age groups included and methods for estimating direct and indirect costs.

- Scant evidence is available on the economic impacts of obesity that are comparable across income contexts for policy and advocacy.

What are the new findings?

- We estimate obesity costs between $0.8 \%$ and $2.4 \%$ of gross domestic product (GDP) in 2019 in the eight countries in the study.

- Our projections reveal an increasing trend in obesity costs as a percentage of GDP over time, estimated to reach $2.4 \%$ of GDP in Spain and up to $4.9 \%$ in Thailand in 2060.

- The economic impacts of obesity are substantial and reach a similar magnitude in low-income and middleincome countries as in high-income contexts.

- Maintaining or reducing the prevalence of obesity can reduce the economic impacts of obesity in the future.

What do the new findings imply?

- Quantifying the economic impacts of obesity will help stakeholders understand the importance of addressing obesity through systemic solutions and is a tool for national and international advocates to encourage policy actions.

- There is need for a concerted increase in national efforts to combat the global rise in obesity prevalence and overcome the existing policy inertia that has hampered progress on obesity policy implementation.

each year, with over half occurring under the age of $70 .^{3}$ The COVID-19 pandemic also revealed obesity as a significant factor in infectious disease morbidity and mortality. ${ }^{4}$ 
Obesity is a complex chronic disease process resulting from the interaction of various factors including genetic susceptibility, high energy-dense nutrition, low physical activity and stress. ${ }^{2}$

The multifactorial and chronic nature of overweight and obesity leads to economic impacts for individuals and nations. Most evident are the direct healthcare costs associated with treating obesity-attributable diseases. Individuals living with obesity are significantly more likely to use home healthcare services, have more outpatient visits, be prescribed more medications, be admitted to a hospital and undergo surgery than individuals with lower weight. ${ }^{56}$ Finally, individuals with obesity experience higher costs of care and longer hospital stays. ${ }^{78}$

The economic impacts of obesity include indirect costs resulting from lost or reduced productivity and human capital. Studies from multiple countries show that individuals with obesity miss more days of work (absenteeism) than individuals without obesity, and work at less than full capacity when they are at work (presenteeism).${ }^{9}$ Obesity also increases the chances of unemployment and has a negative impact on wages. ${ }^{10}{ }^{11}$ Finally, premature deaths from obesity-attributable diseases imply a loss of potential future contributions to the economy. As with economic studies of other diseases, studying the economic costs of obesity does not imply and should not be misconstrued as meaning that individuals living with obesity create or are responsible for costs or economic losses. Rather, an increasingly obesogenic environment, both directly and through individual epigenetic changes, leads to an increased prevalence of obesity and its associated economic impacts. Although difficult to measure, weight bias also imposes economic and other costs, ${ }^{12}$ further underscoring the importance of not blaming individuals experiencing obesity.

Obesity has been shown to have substantial economic impacts in some countries, with estimates of the costs of medical care and reduced productivity ranging from $0.13 \%$ of GDP in Thailand to $9.3 \%$ in the USA. ${ }^{1314} \mathrm{~A}$ review of the literature identified 59 studies of economic impacts of obesity published since 2010, a full list of which can be found in the online supplemental appendix. However, most of these studies come from high-income countries, use a healthcare system perspective, and vary considerably in types of outcomes reported, obesityrelated diseases included, age groups included, types of costs and methodologies employed in estimating direct and indirect costs.

This study aims to estimate the current and future economic impacts of obesity using a modelling framework that can be applied to different national contexts around the world and be updated over time. It also assesses the effect of two hypothetical future obesity prevalence scenarios on economic impacts and presents results for eight countries selected to represent a range of geographies and income levels and for which adequate data was available. Cross-country analyses of the economic impacts of obesity are an important way to dispel myths and misunderstandings about the prevalence and causes of obesity, as well as factors that can reduce it. Our review of country studies and methodologies highlights the need to estimate the current and projected economic impacts of obesity across diverse countries in a comparable manner. It is especially important to understand the presence of obesity in low-income and middleincome countries (LMICs) but we found only one crosscountry study that included countries that are not high income. ${ }^{15}$ Hence, this study seeks to fill that gap. Quantifying the magnitude of economic impacts of obesity helps policy-makers and other stakeholders better understand the scope of the challenge, supports prioritisation and resource allocation efforts, as well as providing a crucial tool for national and international advocates to urge policy-makers to respond with effective policies. ${ }^{16}$

\section{METHODS}

We employed a cost-of-illness approach ${ }^{17} 18$ to estimate the economic impacts of overweight and obesity in eight countries from a societal perspective in 2019 (baseline) and projected impacts in 2060. This approach translates the adverse effect of obesity into monetary terms, ${ }^{17}$ which is useful for understanding the impact of obesity for policy prioritisation and agenda setting. In addition, it is useful for facilitating cross-national comparisons of obesity consequences across different contexts. ${ }^{19}$ Overweight is defined as a body mass index (BMI) of $25 \mathrm{~kg}$ / $\mathrm{m}^{2}$ to $29.9 \mathrm{~kg} / \mathrm{m}^{2}$ in adults and obesity as a BMI of $30 \mathrm{~kg} /$ $\mathrm{m}^{2}$ and above; while for children, overweight is defined as weight 1-2 standard deviations (SD) above the median weight and obesity as more than $2 \mathrm{SD}$ above the median. ${ }^{1}$ Hereafter, we will use the term 'obesity' to refer to both overweight and obesity. The countries in this studyAustralia, Brazil, India, Mexico, Saudi Arabia, South Africa, Spain and Thailand-were selected to represent diverse geographic and economic national contexts and based on general data availability. We included 28 obesityrelated diseases (online supplemental appendix 1: table 1) from the Global Burden of Disease (GBD) Study with evidence of obesity risk linkages. ${ }^{3}$

Under the cost-of-illness approach, the economic impacts of an illness are divided into direct costs and indirect costs (figure 1). In this study, direct costs consist of medical costs and non-medical costs (specifically, the travel and time required to receive care). Indirect costs include economic loss from premature mortality and productivity losses from absenteeism and presenteeism. Other relevant cost components such as long-term disability and early retirement $\operatorname{costs}^{9}$ were not included as it was not feasible to measure these across countries. Also, in some societies there may be costs associated with weight bias (eg, lower academic achievement, reduced emotional support, reduced likelihood of promotion) and in others there may be a premium associated with obesity $^{20}$; however, the magnitude and direction of these impacts have not been studied across countries. ${ }^{12}$ 


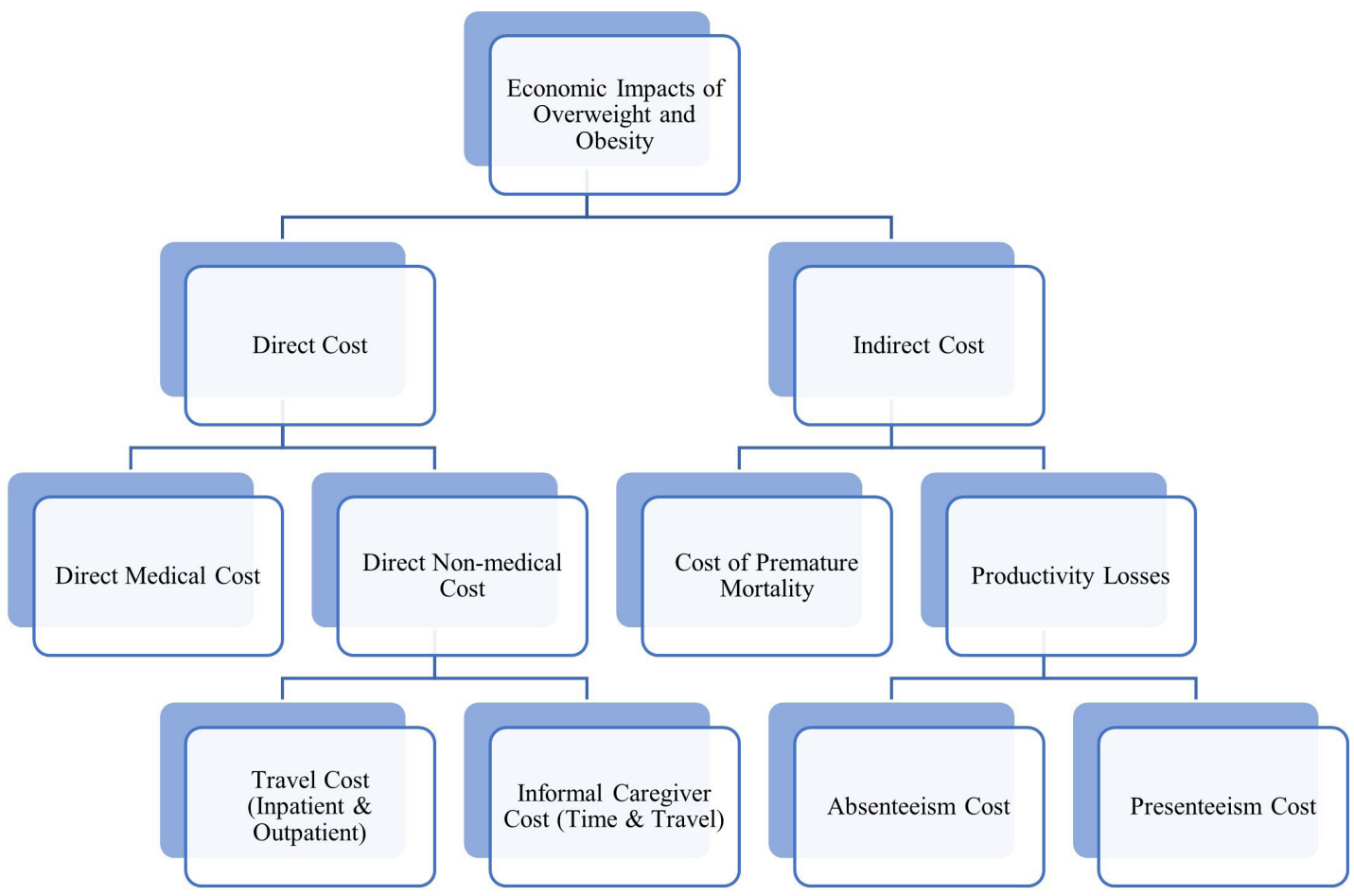

Figure 1 Cost components framework.

We searched PubMed and Google Scholar for peerreviewed studies and grey literature on the economic impacts of obesity in LMICs, published between 1 January 2010 and December 2019. The PubMed search strategy included MeSH terms for overweight, obesity, world regions and economics, as well as the name of each LMIC (as defined by the World Bank) and synonyms for LMIC status. We identified 59 studies on the economic impacts of obesity, a full list of which can be found in online supplemental appendix 4 . Data for model parameters are from peer-reviewed literature and publicly available global databases (see table 1). Data on obesity prevalence and obesity attributable deaths were drawn from the NCD Risk Factor Collaboration (NCD-RisC) study $^{1}$ and 2019 GBD Study, ${ }^{21}$ respectively. Data on national healthcare expenditure were drawn from the WHO Global Health Expenditure Database. ${ }^{22}$ Annual/daily wage data, GDP and employment rates were sourced from the World Bank's World Development Indicators database. ${ }^{23}$ Parameters such as population, life expectancy and background death rates were drawn from the United Nations Population Division. ${ }^{24}$ The remaining model parameters-average travel cost; average inpatient and outpatient consultations; hospitalisation days; absenteeism days and presenteeism rate-were sourced from peer-reviewed studies. Where country-specific data were not available, we applied data from another country in the same income group (table 1).

\section{Estimation of direct costs at baseline}

Direct costs are typically divided into medical and nonmedical costs in the cost-of-illness literature. Direct medical costs measure healthcare goods and services consumed due to obesity-attributable diseases and include curative, rehabilitative and preventative care, ancillary services, and medical goods. ${ }^{15}$ To estimate the direct medical cost or obesity-attributable healthcare expenditures, we identified studies from our literature search that reported the proportion of health expenditure attributable to obesity or obesity-attributable fractions (OAF) for a country. We found the OAFs from the Organisation for Economic Co-operation and Development (OECD) report (for the 52 countries in the report) to be the most appropriate because they are based on the GBD study and include the same number of obesityrelated diseases as this paper (online supplemental appendix 1: table 1). ${ }^{15}$ All eight countries in this study were included in the OECD report except for Thailand. The direct medical costs in 2019 were calculated by multiplying the total health expenditure (THE) of a country in 2019 by the proportion of health expenditure attributed to obesity (OAF).

$$
\text { Direct Medical Cost }=\mathrm{OAF} \times \mathrm{THE}
$$

To estimate OAF for countries not included in the OECD report (Thailand) and for projections, a simple linear regression of OAFs on total obesity prevalence was conducted using the 52 countries in the OECD report. The 52 countries account for about $95 \%$ of total health expenditure globally. There is a significant positive association between OAF and obesity prevalence $(\beta=0.094$, $\mathrm{F}=12.92, \mathrm{p}=0.001$ ) (online supplemental appendix 1 : figure 1). The regression outputs from the estimated equation were used to estimate the OAFs for all countries. We also apply the regression outputs to estimates of projected obesity prevalence to calculate future OAFs as explained subsequently. We used the estimated OAFs from the regression outputs in computing direct medical costs in 2019 for all eight countries instead of the raw values from the OECD report to prevent discordance 
Table 1 Model summary: parameters and data sources

\section{Parameter \\ Direct medical cost: Healthcare expenditures}

Total healthcare expenditures

Obesity-attributable fraction of healthcare expenditures for Australia, Brazil, India, Mexico, Saudi Arabia, South Africa and Spain

\section{Direct non-medical cost: Travel costs for inpatient and outpatient visits for persons with obesity}

Average travel cost to and from health facility: Australia

Average travel cost to/from health facility: Brazil

Average travel cost to/from health facility: India

Average travel cost/from health facility: Mexico

Average travel cost to/from health facility: Saudi Arabia

Average travel cost to/from health facility: South Africa

Average travel cost to/from health facility: Spain

Average travel cost to/from health facility: Thailand

Average no. of hospitalisations by population with obesity: Brazil, South Africa, India, Mexico, Thailand

Average no. of hospitalisations by population with obesity: Australia, Saudi Arabia

Average no. of hospitalisations by population with obesity: Spain

Average no. of outpatient visits by population with obesity: Brazil, South Africa, India, Mexico, Thailand

Average no. of outpatient visits by population with obesity: Australia, Saudi Arabia, Spain

Obesity prevalence

\section{Direct non-medical cost: Informal caregiver (ICG) travel cost}

Average travel cost to and from health facility

Average no. of hospitalisations by population with obesity

Obesity prevalence

\section{Direct non-medical cost: ICG time cost}

Average daily wage: Australia

Average daily wage: India

Average daily wage: Brazil, Mexico, Saudi Arabia, South Africa, Spain, Thailand

Average length of hospitalisation of population with obesity: Australia, Saudi Arabia, Spain

Average length of hospitalisation of population with obesity: Brazil, South Africa, India, Mexico, Thailand

Obesity prevalence

\section{Indirect cost: Premature mortality}

Obesity-attributable mortality

Life expectancy

Background death rates

Annual gross domestic product per capita

\section{Data source}

WHO Global Health Expenditure Database ${ }^{22}$

'The Heavy Burden of Obesity: The Economics of Prevention', Organisation for Economic Co-operation and Development (OECD) Health Policy Studies ${ }^{15}$
Consumption and Socioeconomic Classification in Brazil: a Study Based on the Brazilian Family Expenditure Survey ${ }^{50}$

Key Indicators of Household Expenditure of Services and Durable Goods ${ }^{51}$ Mexico: Encuesta Nacional de Ingresos y Gastos de los Hogares ${ }^{52}$

Saudi Arabia Household Income and Expenditure Survey ${ }^{53}$

South Africa: Measuring household expenditure on public transport technical report ${ }^{54}$

Spain: Survey of Family Budgets ${ }^{55}$

The 2017 Household Socioeconomic Survey Whole Kingdom ${ }^{56}$

Kudel I et $a{ }^{57}$ This source provides country-specific data for Brazil and was used for other LMICs (South Africa, India, Mexico and Thailand).

Korda et $a l^{58}$ This source provides country-specific data for Australia and was also used for Saudi Arabia, the other high-income country for which data was not available.

Espallardo et $a l^{59}$

Kudel et $a l^{57}$ This source provides country-specific data for Brazil and was used for other LMICs (South Africa, India, Mexico and Thailand).

Espallardo et $a{ }^{59}$ This source provides country-specific data for Spain and was used for other high-income countries (Australia and Saudi Arabia).

N.C.D. Risk Factor Collaboration (NCD-RisC) $)^{60}$

Same as patient average travel cost to and from health facility

Same as above

N.C.D. Risk Factor Collaboration (NCD-RisC) ${ }^{60}$

\section{OECD.Stat Database ${ }^{61}$}

ILO Global Wage Report ${ }^{62}$

The ILOStat database contains country-specific data for the listed countries. ${ }^{63}$

Korda et a ${ }^{58}$ This source provides country-specific data for Australia and was used for other high-income countries (Saudi Arabia and Spain).

Ordoñez et al ${ }^{64}$ This source provides country-specific data for Brazil and was used for other LMICs (South Africa, India, Mexico and Thailand). N.C.D. Risk Factor Collaboration (NCD-RisC) $)^{60}$

Global Burden of Disease Study (GBD) $)^{21}$

United Nations Population Division (UNPD) ${ }^{24}$

United Nations Population Division (UNPD) ${ }^{24}$

World Bank World Development Indicators DataBase ${ }^{23}$

\section{Indirect cost: Absenteeism}

Excess days absent: No of additional days of absenteeism taken by an average obese employee compared with an Kudel et $\left.a\right|^{57}$ This source provides country-specific data for Brazil and was used for other LMICs (Mexico and Thailand). 
Table 1 Continued

\begin{tabular}{|c|c|}
\hline Parameter & Data source \\
\hline Excess days absent: Australia, Saudi Arabia & $\begin{array}{l}\text { Keramat et al }{ }^{65} \text { This source provides country-specific data for Australia and } \\
\text { was used for the other high-income country for which data was not available } \\
\text { (Saudi Arabia). }\end{array}$ \\
\hline Excess days absent: Spain & Catalina-Romero et a ${ }^{67}$ \\
\hline Employment rates & World Bank World Development Indicators Database ${ }^{23}$ \\
\hline \multicolumn{2}{|l|}{ Indirect cost: Presenteeism } \\
\hline $\begin{array}{l}\text { Excess presenteeism rate: rate of reduced productivity among } \\
\text { obese employees: Brazil, South Africa, India, Mexico, Thailand }\end{array}$ & $\begin{array}{l}\text { Kudel et a }\left.\right|^{57} \text { This source provides country-specific data for Australia and was } \\
\text { used for other LMICs (South Africa, India, Mexico and Thailand). }\end{array}$ \\
\hline Excess presenteeism rate: Australia & Weighing the cost of obesity: A call for action by $P w C^{68}$ \\
\hline Excess presenteeism rate: Saudi Arabia, Spain & $\begin{array}{l}\text { Hayman }{ }^{69} \text { This source provides country-specific data for Saudi Arabia and } \\
\text { was used for the other high-income country for which data was not available } \\
\text { (Spain). }\end{array}$ \\
\hline
\end{tabular}

LMICs, low-income and middle-income countries.

between current and future direct medical costs and to allow for useful comparisons across years (see the Methods section in online supplemental appendix for more details).

Direct non-medical costs measure the additional costs incurred during the process of seeking care, such as travel to health facilities or doctor appointments, costs incurred by informal caregivers (ICGs), food and lodging during inpatient care, and home modifications. This study includes an estimation of travel expenses and ICG costs only as there are not reliable data about other direct non-medical costs from which to develop cross-country estimates.

Travel costs were estimated separately for inpatient (hospitalisation) and outpatient care. We calculated this by multiplying the average travel cost (ATC) per trip (proxied by country-specific daily average transportation expenditure per capita) by the population with obesity. The formulae for these components are:

$$
\begin{aligned}
\text { Inpatient Travel Costs } & =\mathrm{ATC} \times \mathrm{N}_{\text {in }} \\
& \times \text { Population with Obesity } \\
\text { Outpatient Travel Costs } & =\text { ATC } \times \mathrm{N}_{\text {out }} \\
& \times \text { Population with Obesity }
\end{aligned}
$$

where ATC is the average travel cost to and from health facilities; $\mathrm{N}_{\text {in }}$ and $\mathrm{N}_{\text {out }}$ are the average number of inpatient and outpatient consultations by the population with obesity compared with the normal weight population, respectively; and Population with Obesity $=$ Obesity Prevalence $\times$ Total Population

ICG costs were estimated for inpatient care and include both travel and time costs during inpatient care. ICG travel cost is calculated the same as inpatient travel cost. ICG time costs denote the income loss of ICGs for time spent tending to a hospitalised family member or friend suffering from an obesity-attributable disease. We calculate this as the average wage lost from the time spent in the hospital.

$$
\begin{aligned}
\text { ICG Time Costs } & =\text { Average Daily Wage } \times \mathrm{N}_{\mathrm{d}} \\
& \times \text { Employed ICGs for Pop. with Obesity }
\end{aligned}
$$

where Employed ICGs for Pop. with obesity = Employment rate $\times$ Working Age Pop. $\times$ Obesity Prevalence; $N_{d}$ is the average number of hospitalisation days by the population with obesity compared with the normal weight population. ${ }^{25}$ Productivity loss from inpatient/outpatient care for the population with obesity is assumed to be included within the indirect cost from absenteeism described below.

\section{Estimating indirect costs at baseline}

Indirect costs represent the economic loss due to premature mortality and morbidity and includes the following components: economic loss from premature mortality, missed days of work (absenteeism) and reduced productivity while at work (presenteeism). For absenteeism and presenteeism costs, we assume the same employment rates by BMI status. While it is plausible that the population with obesity may have a lower employment rate compared with the population without obesity, the existing evidence is mixed and inconclusive. ${ }^{26-33}$

Economic loss from premature mortality is calculated as the number of years of potential life lost by individuals (by age group and sex cohort) who died from obesity multiplied by the economic value of a life year. To quantify the number of years of potential life lost due to obesity, we estimate how many people in each age and sex cohort would have been alive in future years (based on life expectancy) if they had not died from obesity-attributable diseases, while taking into account background death rates from other causes. Background 
death rates are drawn from country-specific life tables (table 1). ${ }^{34}$ We used GDP per capita as a proxy for the economic value of a life year (VLY) to capture economic loss from premature mortality. Other proxies that have been used in estimating cost of premature mortality include wages and the value of a statistical life year (see online supplemental appendix 1: box 1). Our choice of GDP per capita is driven by an inclination to value the economic contribution of every individual in the society across the lifecourse irrespective of employment status. This brings an equity lens to how economic contributions are counted. Furthermore, as part of sensitivity analysis for the upper bound of premature mortality cost, we adjust GDP per capita with a GDP multiplier (online supplemental appendix 1: table 2) for the gains in health or life expectancy that would have occurred in the absence of obesity attributable deaths as developed by the Lancet Commission on Investing in Health. ${ }^{35}$ The economic cost of obesity-attributable mortality for each sex (S) and age (A) cohort included in the model is calculated as the sum of annual costs from age of death $(\mathrm{i}=0)$ to remaining life expectancy when no persons from the cohort would remain alive if they had not died of obesity-attributable diseases, where VLY is the value of a life year proxied by GDP per capita in model death year and People is the number of people who would have still been alive in year $i$ had they not died of obesity-attributable disease.

$$
\begin{array}{r}
\text { Obesity-attributable mortality } \\
\text { cost in cohortsA }
\end{array}=\sum_{i=0}^{N} V L Y \times(1+r)^{-(i)} \times \text { People }_{\mathrm{i}}
$$

For all age and sex cohorts, all future costs are assigned to the year in which death occurred, discounted at a rate of $3 \%$ per year to obtain the net present value, and added up to give the total economic cost of obesity-attributable premature mortality.

Productivity losses due to absenteeism occur when employees miss work due to illness or health conditions related to obesity. The calculation for the cost of lost productivity due to excess absenteeism among the working population with obesity is:

Absenteeism Cost = Employed Pop. with Obesity

$$
\times \text { Excess Days Absent } \times \text { Average Daily Wages }
$$

where Employed Pop.with Obesity = Employment rate $\times$ Working Age Pop. $\times$ Obesity Prevalence; Excess Days Absent=Average number of additional days of absenteeism by working population with obesity compared with normal weight working population.

Productivity losses due to excess presenteeism refers to reduced productivity while at work due to obesity-related impairment and disability. The calculation for the cost of lost productivity due to excess presenteeism among the working population with obesity is:

Presenteeism Cost = Employed Pop. with Obesity

$\times$ Excess Presenteeism Rate $\times$ Average Annual Wages where Employed Pop.with Obesity = Employment rate $\times$ Working Age Pop. $\times$ Obesity Prevalence; Excess Presenteeism Rate $=$ Rate of reduced productivity among employees with obesity.

\section{Estimating future costs}

The projections of obesity's economic impacts are an extension of the modelling approach used for the current impacts' estimation. We calculated costs for future years using projected estimates for the different parameters in the model. The index/baseline year for estimating current impacts is 2019, the most recent year with available mortality data from the GBD study. Our projections are therefore from 2020 to 2060. Online supplemental appendix 1: table 3 shows the secondary sources of data for parameters for which existing long-term projections were found. Some parameters such as number of inpatient and outpatient consultations, hospitalisation days, absenteeism days and presenteeism rate were assumed to stay constant. We adjusted travel costs for inflation in the future using GDP Deflator projections. We modelled future estimates for parameters with no existing long-term projections. These are annual wages, obesity prevalence, OAF of health expenditures and obesity-attributable mortality. For future annual wages, we extrapolated historical average annual wage growth to 2060. Future estimates for obesity prevalence, OAF of health expenditures, and obesity-attributable mortality were modelled as described below.

Future obesity prevalence: We used a multivariate autoregression approach to model changes in annual country-level overweight and obesity prevalence from 1975 to 2016 for males and females in two age-groups (less than 20 years and 20 years and above) with data from the NCD-RisC study. ${ }^{1}$ This model combines an autoregressive component (past prevalence observations), a differencing step to ensure stationarity and factors that influence prevalence as covariates to predict future obesity prevalence. Our model takes the following form for country $i$, year $t$ and sex $s$ :

$$
\Delta \mathbf{Y}_{i, s, t}=\alpha+\sum_{\mathbf{h}=1}^{\mathbf{n}} \boldsymbol{\beta}_{\mathbf{h}} \Delta \mathbf{Y}_{i, s, t-h}+\boldsymbol{X}_{i, s, t}{ }^{\prime} \theta+\varepsilon_{i, s, t}
$$

Where $\mathbf{Y}_{i, s, t}$ is the differenced transformation of obesity prevalence with n degrees of lag included in the model; $\boldsymbol{X}_{i, s, t}$ denotes factors that influence obesity prevalence; and $\alpha$ and $\varepsilon_{i, s, t}$ refers to the intercept and error term respectively. Factors comprising $\boldsymbol{X}_{i, s, t}$ are proxies for demographic changes and urbanisation which have been linked to changes in obesity prevalence globally. These include the annual percentage of a country's population in specific age intervals (under 20 years, 20-54 years, 54-74 years and above 75 years which reflect global age trends in obesity prevalence derived from $\mathrm{Ng} e t a l^{36}$ ) as a measure of population changes over time and annual proportion of a country's population living in urban areas as a measure of urbanisation. All predictor variables are first differenced because we are interested in how their changes over time influence obesity prevalence. 
The estimated model is then applied to forecast future obesity prevalence using projected estimates of population growth and urbanisation (see online supplemental appendix 1 for more details).

Future OAF of health expenditure: As earlier explained, we obtained estimates of OAFs for 52 countries from the OECD report. ${ }^{15}$ We then estimated a simple linear regression of these OAFs on obesity prevalence. The regression outputs (coefficient and intercept) together with projected obesity prevalence estimates were then used to generate future estimates of OAFs.

Future Obesity-attributable mortality: We calculated all-cause mortality (total deaths) from 2020 to 2060 using the annualised rate of change of projections for obesityrelated disease mortality from Foreman and colleagues. ${ }^{37}$ We then calculated population attributable fraction (PAF) of obesity mortality for each future year by sex, cause and age group. We used the calculated PAF to generate obesity-attributable deaths for projected years by sex, age group and cause. For more details, see online supplemental appendix 1.

Hypothetical scenarios: In addition to estimating future economic costs based on projected obesity prevalence, we also estimated the impact on the projected economic costs using two scenarios of lower prevalence in the future. Projections are not predictions, hence future obesity prevalence and other model parameters may diverge from projected estimates, which are based largely on historical trends. Therefore, in addition to estimating future economic costs based on projected prevalence, we also developed two hypothetical scenarios for economic impacts of obesity keeping in mind that no country has been able to reduce obesity prevalence ${ }^{36}$ and there have been indications of stabilisation in only a handful of countries. ${ }^{15}$ The two hypothetical scenarios are: (1) a 5 percentage point reduction in projected obesity prevalence (by sex and age group) for each year and (2) holding obesity prevalence (by sex and age group) constant at 2019 levels.

\section{Currency conversions}

All costs are in 2019 constant US dollars. Data for GDP per capita, wages and travel costs were collected in local currency units where possible, adjusted for inflation to 2019 values, and converted to US\$ using average annual exchange rates. Purchasing power parity (PPP) costs were also calculated, using PPP conversion factors drawn from the World Bank World Development Indicators Database..$^{23} 38$

\section{RESULTS}

\section{Current economic impacts of obesity}

Total obesity costs per capita range from US $\$ 17$ in India to US $\$ 940$ in Australia. Obesity results in an impact comparable to $1.76 \%$ of GDP on average across the eight countries, ranging from $0.80 \%$ of GDP in India to $2.42 \%$ in Saudi Arabia (figures 2 and 3). Table 2 provides

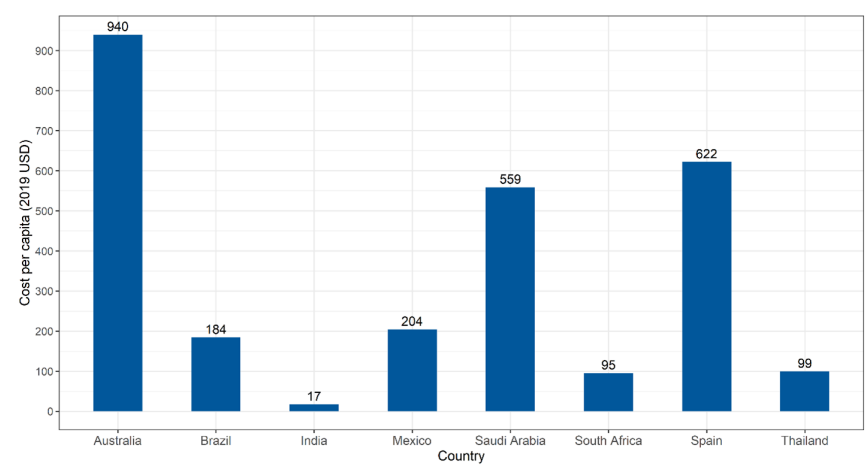

Figure 2 Total cost of obesity in 2019 in per capita terms (in 2019 US\$).

a comparison of total costs and costs per capita in US dollars, PPP dollars and as a percentage of GDP.

Table 3 shows economic impacts by cost components and figure 4 shows total costs by country. Medical costs make up $90 \%$ of direct costs on average across all countries. Time cost of informal caregivers constitute more than $90 \%$ of direct non-medical costs on average across all countries. The cost of premature mortality constitutes a substantial proportion of indirect costs (about $56 \%-92 \%$ ) across all countries. We did a sensitivity analysis which values the life expectancy gains from avoiding premature mortality at a multiple of GDP, following recommendations from the Lancet Commission on Investing in Health. This results in total costs of 2.59\% of GDP on average across the eight countries, ranging from $1.70 \%$ of GDP in India to $4.16 \%$ in South Africa (table 3). These results, which place a higher value on premature mortality costs, represent a $57 \%$ increase in total costs on average across the eight countries, ranging from a $19 \%$ increase in Australia to a $163 \%$ increase in South Africa.

Obesity prevalence, wage and employment data were disaggregated by sex for all eight countries. Economic impacts of obesity are typically higher for males compared with females (figure 5). This difference is driven by obesity prevalence, wages and sex differences in employment.

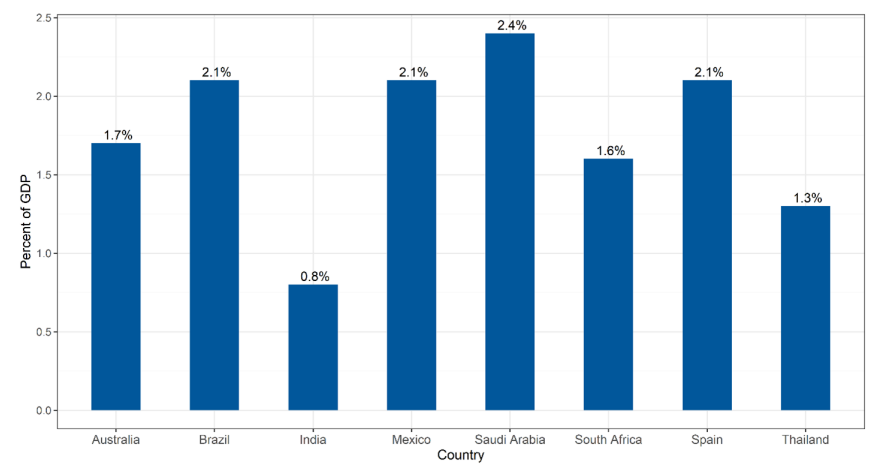

Figure 3 Total cost of obesity in 2019 as a percentage of GDP. GDP, gross domestic product. 
Table 2 Total current costs of obesity and costs of obesity per capita expressed in 2019 US\$, 2019 PPP US\$, and as a percentage of GDP

\begin{tabular}{llllll}
\hline & $\begin{array}{l}\text { Total costs, 2019 } \\
\text { US\$ (billions) }\end{array}$ & $\begin{array}{l}\text { Total costs per capita, Total costs, 2019 } \\
\text { 2019 US\$ }\end{array}$ & $\begin{array}{l}\text { Total costs per } \\
\text { PPP (billions) }\end{array}$ & $\begin{array}{l}\text { Total costs as a } \\
\text { percentage of GDP }\end{array}$ \\
\hline Australia & 23.68 & 940 & 24.17 & 959 & 1.74 \\
Brazil & 38.76 & 184 & 68.67 & 325 & 2.11 \\
India & 23.24 & 17 & 78.23 & 57 & 0.80 \\
Mexico & 26.04 & 204 & 54.57 & 428 & 2.05 \\
Saudi Arabia & 19.16 & 559 & 41.89 & 1222 & 2.42 \\
South Africa & 5.54 & 95 & 12.08 & 206 & 1.58 \\
Spain & 29.06 & 622 & 44.60 & 954 & 2.09 \\
Thailand & 6.89 & 99 & 17.43 & 250 & 1.27 \\
\hline
\end{tabular}

GDP, gross domestic product; PPP, purchasing power parity.

\section{Future economic impacts of obesity}

Table 4 and figures $6-8$ summarise estimated future costs based on projections of model parameters to 2060. Obesity costs across all countries are projected to increase due to rising obesity prevalence, population changes and economic growth. Between 2020 and 2060, obesity costs are projected to double in Spain and increase by 19-fold in India. As a percentage of projected GDP, total costs in 2060 are estimated to be an average of $3.57 \%$ across the eight countries, ranging from $2.43 \%$ in Spain to $4.88 \%$ in Thailand. See online supplemental appendices 2 and 3 for additional figures and tables.

\section{Hypothetical scenarios}

Our first hypothetical scenario depicts projected economic impacts if there is a 5 percentage points reduction in obesity prevalence from the projected levels (by sex and age). Using this prevalence scenario with all other projected parameters remaining unchanged, we estimate a slight reduction in obesity's economic cost trajectory compared with baseline projections. As a percentage of projected GDP, total costs in 2060 will range from $2.32 \%$ in Spain to $4.70 \%$ in Thailand (figure 9). Compared with baseline projections, this scenario implies an average annual savings of approximately $5.18 \%$ across all eight countries between 2021 and 2060 (table 5).

Our second hypothetical scenario projects obesity's economic impacts while holding obesity prevalence constant. This is consistent with the WHO NCD Global Monitoring Framework target \#7 to halt the rise in obesity. ${ }^{39}$ Keeping obesity prevalence at 2019 levels from 2020 to 2060 is equivalent to an average annual reduction in prevalence ranging from $9 \%$ to $22 \%$ across countries compared with baseline prevalence projections (table 5). As a percentage of projected GDP, total costs in 2060 will range from $1.44 \%$ in India to $4.14 \%$ in Mexico, translating to average annual savings of $13.18 \%$ compared with baseline projection costs (figure 10).

\section{DISCUSSION}

This study uses cost-of-illness methodology to assess the economic impacts of obesity in eight countries from a societal perspective. We estimate obesity costs between $0.80 \%$ and $2.42 \%$ of GDP in 2019 in the eight countries. To put this into context, annual GDP growth rate in 2019 averaged $1.6 \%$ among the eight countries, ranging between $-0.12 \%$ (Mexico) and $5 \%$ (India) ${ }^{23}$ It is therefore reasonable to view the economic impact of obesity as a significant hindrance to economic development. However, these estimates are still conservative. Our sensitivity analysis shows that putting a higher value on gains in life expectancy from avoiding premature mortality would yield a higher economic loss from obesity.

While our results are in a comparable range to the most recent multicountry study of obesity's economic impact $(\mathrm{OECD}),{ }^{15}$ they are higher than earlier studies in some of the countries as we include the impacts of obesity on more diseases. For example, Pitayatienanan et al estimate healthcare costs (outpatient and inpatient visits only) in Thailand for 13 obesity-related diseases in 2009 as 5.5 billion Thai baht (approximately US $\$ 220$ million in 2019), compared with our estimate of US\$1.3 billion in obesity-attributable healthcare expenditure for 26 obesity-related diseases. In Brazil, Bahia et al estimate the obesity-attributable public healthcare expenditures for 14 diseases in 2010 US $\$$ as 221 million compared with our estimate of US $\$ 14$ billion in combined public and private obesity-attributable healthcare expenditure for 26 obesity-related diseases. ${ }^{40}$ In addition, some of the difference in results can be attributed to a rise in obesity prevalence during the interim (an increase of $11 \%$ in Thailand and $8 \%$ in Brazil between the periods of these two studies and 2019). ${ }^{1}$ With regard to societal impacts more broadly, we also use GDP per capita to proxy the economic value of a life year for premature mortality while some studies use minimum or average wage in each country. ${ }^{13} 3541$ Differing sources, availability and granularity of data could also contribute to differences in cost estimates. 


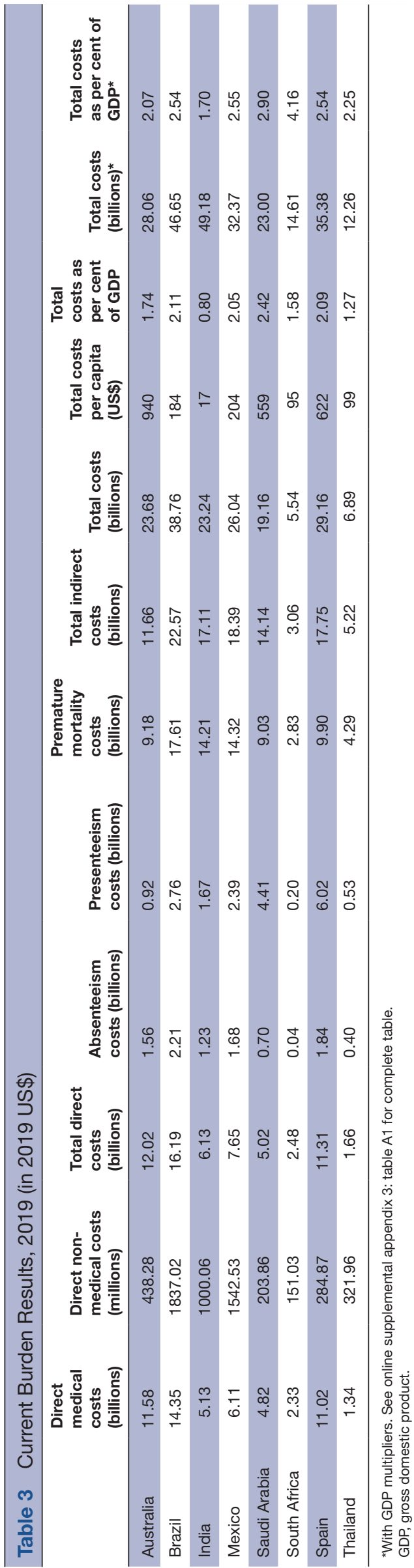

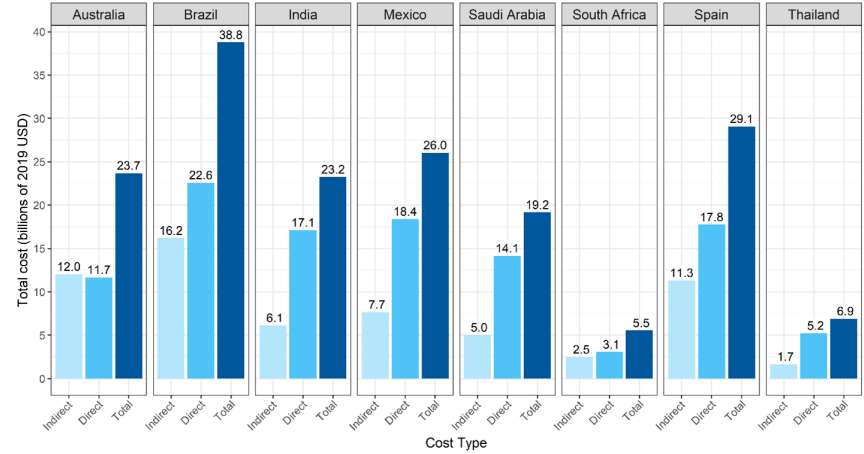

Figure 4 Current costs of obesity in 2019 (in billions of 2019 US\$).

Our findings reveal that the societal impacts of obesity are substantial for countries at different income levels. While high-income countries are known to experience high economic costs from obesity ${ }^{15}$ this study finds that a similar magnitude of impact may be present in LMICs consistent with existing evidence on the double burden of malnutrition. ${ }^{42}$ Differences in economic impact across countries are partly explained by differences in obesity prevalence and obesity-attributable mortality. India has the lowest total obesity prevalence, obesity-attributable mortality, and cost per GDP per cent of the eight countries. On the other hand, Saudi Arabia, with the highest cost per GDP per cent, has the highest total obesity prevalence and also has an above-average obesity-attributable mortality among the eight counties. Other factors that drive differences in total costs between countries include the income levels/economic strength (GDP/capita), wage differences, employment rates, national healthcare expenditure and the age distribution of obesityattributable mortality.

Estimates of obesity's economic impacts that are limited to only direct healthcare costs underestimate the full economic effect of overweight and obesity. Our findings indicate that indirect costs of obesity account for a larger proportion of total cost $(65 \%$ on average across countries) compared with direct costs. However, direct medical costs still impose immediate and sometimes unsustainable burdens on health systems. Examination of the variation in costs by sex in 2019 also generally

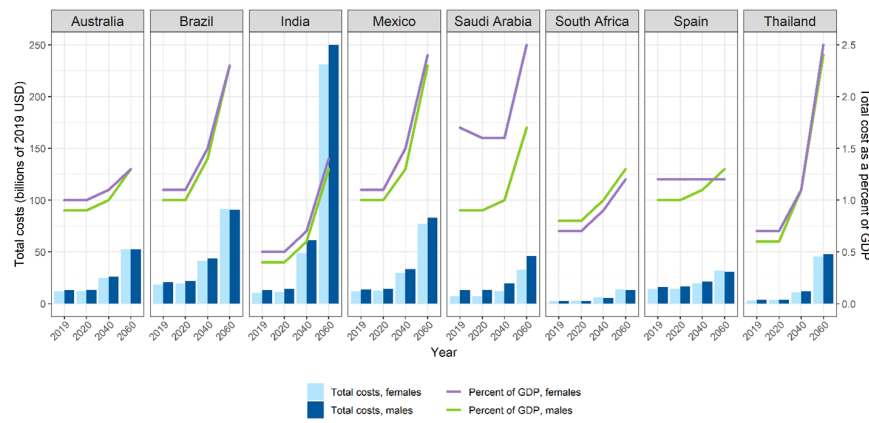

Figure 5 Total cost of obesity by sex (billions of 2019 constant US\$ and as percentage of GDP). GDP, gross domestic product. 


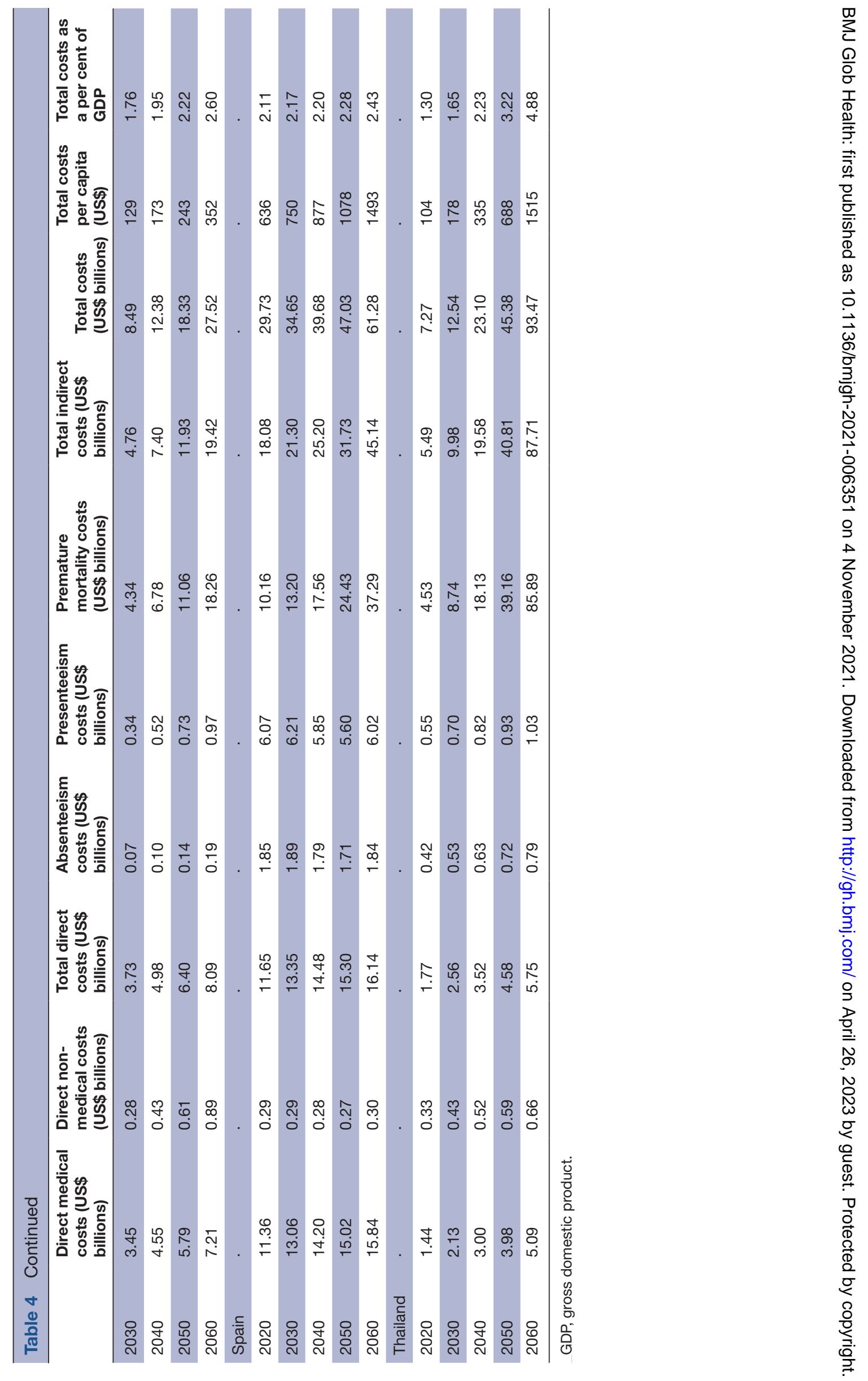




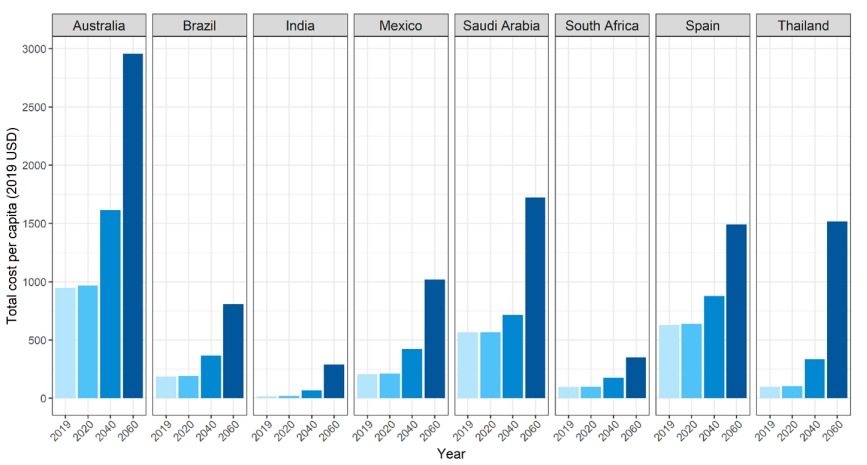

Figure 6 Total costs of obesity per capita (in 2019 US\$), 2019-2060.

indicate a slightly higher cost for males compared with females reflecting differences in obesity prevalence, wages, and employment, which vary by country.

Our projections reveal an alarming trend across all eight countries as the total costs of obesity in 2019 constant US $\$$ is projected to rise at an average rate of between $1.8 \%$ and $6.6 \%$ and cost/GDP is projected to rise at an average rate of $0.4 \%-3.3 \%$ from 2019 to 2060 . This is partly due to a projected rise in obesity prevalence with an average growth rate ranging from $0.7 \%$ to $3.0 \%$ in the same period (online supplemental appendix 3: table A7). We project that the prevalence of obesity will increase to about $57 \%$ of the population in India and to about 93\% of the population in Saudi Arabia in 2060 (figure 8). These estimates are similar to estimates by Kilpi $e t a l$ who adapted the UK Foresight model to estimate that obesity prevalence will rise to $92 \%$ in men and $75 \%$ in women by 2050 in Saudi Arabia. ${ }^{43}$ In another related study of 10 countries in Latin America, obesity prevalence in 2050 is estimated to increase to $90 \%$ of males in Cuba and Panama and to $85 \%$ of females in Chile, Cuba, Nicaragua, Panama, Peru and Uruguay. ${ }^{44}$

Our hypothetical scenarios demonstrate that economic costs to society can be reduced with lower obesity levels. The scenarios underscore the need to take urgent action to reduce potential economic impacts in the future. This will not be achieved if current levels of underinvestment in treatment and the social determinants of obesity continue. Overall, our findings make the case

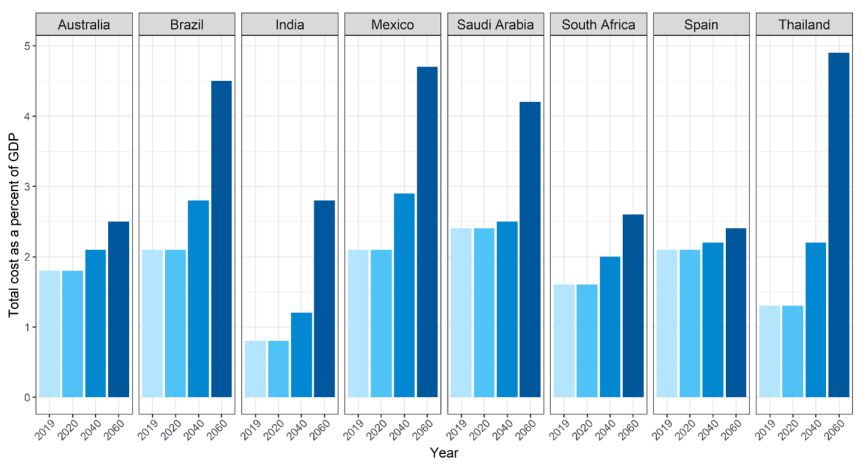

Figure 7 Total costs of obesity as a per cent of GDP, 20192060. GDP, gross domestic product.

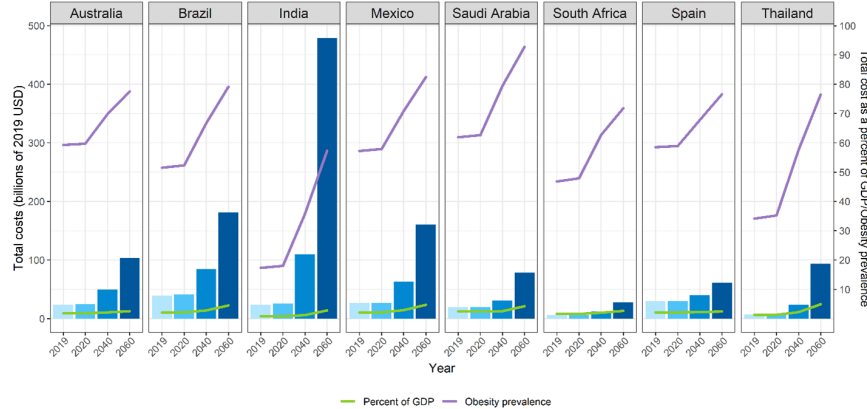

Figure 8 Total costs of obesity (in 2019 constant US\$ and as a per cent of GDP) and obesity prevalence, 2019-2060. GDP, gross domestic product.

for a concerted increase in national efforts to combat the global rise in obesity prevalence and overcome the existing policy inertia that has hampered progress on obesity policy implementation. ${ }^{45}$ WHO's 'best buy' interventions offer an initial set of cost-effective actions for countries to employ, including community wide public education and awareness for physical activity and taxes on sugar-sweetened beverages, ${ }^{46}$ front-of-package labelling and other nutrition profiling schemes. However, many other opportunities to alter the obesogenic environment through food systems, transportation and subsidies have not been widely implemented and evaluated, leaving much room for future study ${ }^{16}$ Efforts to address the economic impacts of obesity must not be left to individuals but focus on altering the complex environmental factors leading to obesity, as well as treatment. The involvement of individuals with obesity in the policy decision-making process and in guiding research is also imperative in achieving equitable allocation and distribution of resources, and for pursuing policies that reduce weight bias. ${ }^{47}$

This study has several limitations. To produce comparable estimates across countries, we used data that are available across both data-rich and data-poor geographical contexts. For some of the parameters, such as absenteeism and presenteeism rates associated with obesity, due to data limitations, we assumed the same value for countries in similar income groups which is a

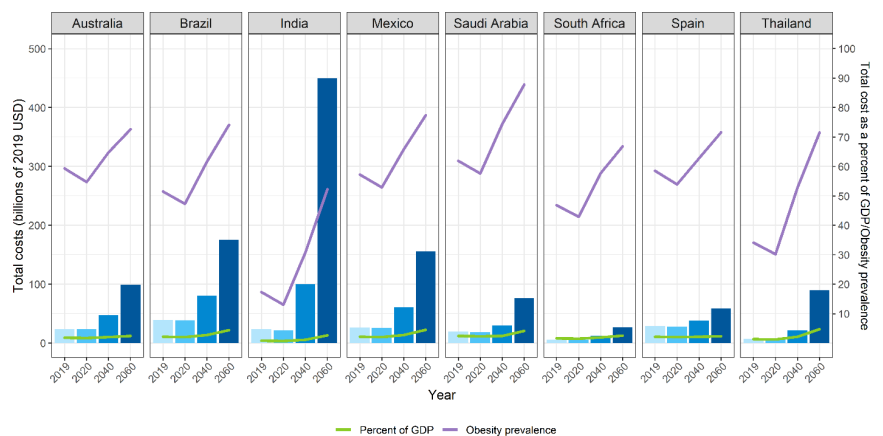

Figure 9 Hypothetical scenario of 5\% reduction in obesity prevalence, total costs (in billions of 2019 constant US\$), total costs as a per cent of GDP, and obesity prevalence, 2019-2060. GDP, gross domestic product. 
Table 5 Annual cost reductions in hypothetical scenarios 1 and 2 between 2020 and 2060

\begin{tabular}{|c|c|c|c|c|c|}
\hline \multirow[b]{2}{*}{ Country } & \multicolumn{2}{|c|}{$\begin{array}{l}\text { Scenario 1: reduction in projected overweight } \\
\text { and obesity prevalence by } 5 \%\end{array}$} & \multicolumn{3}{|c|}{$\begin{array}{l}\text { Scenario 2: keeping overweight and obesity prevalence among } \\
\text { men, women, boys and girls at } 2019 \text { levels through } 2060\end{array}$} \\
\hline & $\begin{array}{l}\text { Average annual cost } \\
\text { reduction (billions of } 2019 \\
\text { US\$) }\end{array}$ & $\begin{array}{l}\text { Percentage cost } \\
\text { reduction (\%) }\end{array}$ & $\begin{array}{l}\text { Average annual cost } \\
\text { reduction (billions of } \\
2019 \text { US\$) }\end{array}$ & $\begin{array}{l}\text { Percentage } \\
\text { cost reduction } \\
(\%)\end{array}$ & $\begin{array}{l}\text { Average annual reduction in } \\
\text { total obesity prevalence from } \\
\text { baseline (\%) (compared with } \\
\text { baseline projection scenario) }\end{array}$ \\
\hline Australia & 2.42 & 4.61 & 5.47 & 8.42 & 9.39 \\
\hline Brazil & 3.83 & 4.35 & 11.21 & 10.12 & 12.98 \\
\hline India & 11.88 & 9.77 & 58.44 & 28.91 & 18.11 \\
\hline Mexico & 2.56 & 3.76 & 6.46 & 7.22 & 10.98 \\
\hline Saudi Arabia & 1.21 & 3.58 & 3.50 & 8.32 & 14.43 \\
\hline South Africa & 0.56 & 4.24 & 1.82 & 11.21 & 13.24 \\
\hline Spain & 2.13 & 5.21 & 3.81 & 8.27 & 8.52 \\
\hline Thailand & 1.57 & 5.92 & 9.32 & 23.00 & 22.26 \\
\hline
\end{tabular}

simplification as there are important variations in labour market behaviour across countries. In addition, while we attempt to account for indirect costs such as absenteeism and presenteeism, there are other indirect effects such as unemployment, long-term disability and early retirement $\operatorname{costs}^{9}$ that are difficult to estimate for data-limited country contexts. These are not included in our analyses nor are intangible effects of obesity that are difficult to quantify in monetary terms such as decreased quality of life. ${ }^{48}$ Estimates of the value of life across countries, genders and age raise ethical challenges that are not fully resolved in this paper. One challenge is simply differences in access to healthcare among countries which hides some of the impacts of obesity in countries that offer less healthcare for obesity-related diseases. Also, we recognise that differences in labour markets, type of and compensation for work, and what is measured by GDP introduces many inequities across populations. We handle these issues with clear and replicable methodology that allows other data inputs to be selected. Individual country studies are the appropriate place to make adjustments for these differences and we suggest here some of the parameters that should be sourced locally whenever possible. Also, while cost-of-illness studies have played a significant role

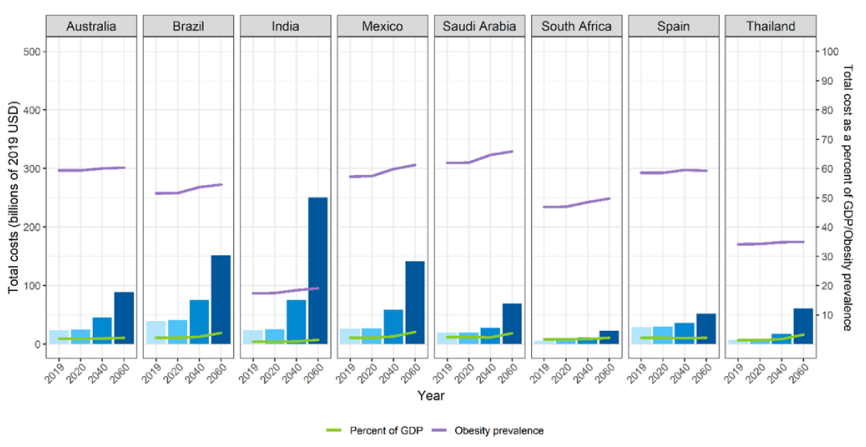

Figure 10 Hypothetical scenario of constant* obesity prevalence, total costs (in billions of 2019 constant US\$), total costs as a per cent of GDP and obesity prevalence, 2019-2060. GDP, gross domestic product. in public health by supporting advocacy for and formulation of healthcare policies, their usefulness in decision making for prioritisation and resource allocation needs to be augmented by a consideration of both costs and benefits.

Our estimates of future obesity prevalence are based on an assumption that historical and current trends relating obesity to age, sex, and nutrition continue, hence we do not model for unforeseeable changes, such as technology progress that could impact the food environment or medical breakthroughs in obesity treatment or prevention. Our cost projections relied on secondary projections from credible sources. Hence, the assumptions of these sources are necessarily transferred to this study as well. Despite these limitations, this study makes an important contribution in quantifying the comparative economic impacts of obesity across eight countries which can be extended to other countries.

\section{CONCLUSION}

Our findings suggest that there are enormous economic impacts associated with obesity across countries irrespective of geography or income level. There is tremendous variation across countries in the level and impacts of obesity but - as seen in these eight countries-historical and current trends demonstrate that economic costs will rise over time. The COVID-19 pandemic has especially affected people living with obesity, thus further bringing obesity to the attention of national policy makers. The findings of this study will be helpful to further strengthen political commitment for national obesity control efforts in these countries. This is greatly needed to achieve levels of investment commensurate to the economic impact. Future analyses will further extend this methodology to other countries and will estimate the effect of COVID-19 on these results.

Contributors A0 contributed to methodology development, data analysis, interpretation of results and writing of manuscript. RN conceived study and contributed to methodology, interpretation of results and writing of manuscript. GS conducted literature search, data collection, created figures/tables and contributed 
to interpretation of results and writing of manuscript. JR coconceived the study and provided guidance on scope and interpretation of results. JW reviewed the paper and provided guidance on interpretation of results.

Funding Support for this work came from World Obesity Federation funds which include an unrestricted educational grant from Novo Nordisk. Novo Nordisk was not involved in the conception and design of the study methodology or in the analysis and interpretation of results.

Competing interests $\mathrm{A} 0, \mathrm{RN}$ and GS report the research was supported by a grant from the World Obesity Federation which received an unrestricted grant from Novo Nordisk; JR reports grants from Novo Nordisk, during the conduct of the study; JW reports grants, personal fees and consultancy fees to his institution from AstraZeneca and Novo Nordisk, personal fees and consultancy fees paid to institution from Boehringer Ingelheim, Napp, consultancy fees paid to institution from Astellas, Janssen, Mundipharma, Lilly, Sanofi, Saniona, Rhythm Pharmaceuticals and Wilmington Healthcare, outside the submitted work.

Patient consent for publication Not required.

Provenance and peer review Not commissioned; externally peer reviewed.

Data availability statement Data are available on reasonable request.

Supplemental material This content has been supplied by the author(s). It has not been vetted by BMJ Publishing Group Limited (BMJ) and may not have been peer-reviewed. Any opinions or recommendations discussed are solely those of the author(s) and are not endorsed by BMJ. BMJ disclaims all liability and responsibility arising from any reliance placed on the content. Where the content includes any translated material, BMJ does not warrant the accuracy and reliability of the translations (including but not limited to local regulations, clinical guidelines, terminology, drug names and drug dosages), and is not responsible for any error and/or omissions arising from translation and adaptation or otherwise.

Open access This is an open access article distributed in accordance with the Creative Commons Attribution Non Commercial (CC BY-NC 4.0) license, which permits others to distribute, remix, adapt, build upon this work non-commercially, and license their derivative works on different terms, provided the original work is properly cited, appropriate credit is given, any changes made indicated, and the use is non-commercial. See: http://creativecommons.org/licenses/by-nc/4.0/.

ORCID iD

Adeyemi Okunogbe http://orcid.org/0000-0002-7486-5176

\section{REFERENCES}

1 Abarca-Gómez L, Abdeen ZA, Hamid ZA, et al. Worldwide trends in body-mass index, underweight, overweight, and obesity from 1975 to 2016: a pooled analysis of 2416 population-based measurement studies in 128.9 million children, adolescents, and adults. The Lancet 2017;390:2627-42.

2 Bray GA, Kim KK, Wilding JPH, et al. Obesity: a chronic relapsing progressive disease process. A position statement of the world obesity Federation. Obes Rev 2017;18:715-23.

3 GBD 2019 Risk Factors Collaborators. Global burden of 87 risk factors in 204 countries and territories, 1990-2019: a systematic analysis for the global burden of disease study 2019. Lancet 2020;396:1223-49.

4 Popkin BM, Du S, Green WD, et al. Individuals with obesity and COVID-19: a global perspective on the epidemiology and biological relationships. Obes Rev 2020;21.

5 Cecchini M. Use of healthcare services and expenditure in the US in 2025: the effect of obesity and morbid obesity. PLoS One 2018;13:e0206703.

6 Wolfenstetter SB, Menn P, Holle R, et al. Body weight changes and outpatient medical care utilisation: results of the MONICA/KORA cohorts S3/F3 and S4/F4. Psychosoc Med 2012;9:Doc09.

7 Padula WV, Allen RR, Nair KV. Determining the cost of obesity and its common comorbidities from a commercial claims database. Clin Obes 2014;4:53-8.

8 Zizza C, Herring AH, Stevens J, et al. Length of hospital stays among obese individuals. Am J Public Health 2004;94:1587-91.

9 Goettler A, Grosse A, Sonntag D. Productivity loss due to overweight and obesity: a systematic review of indirect costs. BMJ Open2017;7:e014632.

10 Biener A, Cawley J, Meyerhoefer C. The impact of obesity on medical care costs and labor market outcomes in the US. Clin Chem 2018;64:108-17.
11 Segal AB, Huerta MC, Aurino E, et al. The impact of childhood obesity on human capital in high-income countries: a systematic review. Obes Rev 2021;22:e13104.

12 Singh K, Russell-Mayhew S, von Ranson K, et al. Is there more to the equation? Weight bias and the costs of obesity. Can J Public Health 2019;110:17-20.

13 Pitayatienanan P, Butchon R, Yothasamut J, et al. Economic costs of obesity in Thailand: a retrospective cost-of-illness study. BMC Health Serv Res 2014;14:146.

14 Milken Institute, ScienceDaily. Economic impact of excess weight now exceeds $\$ 1.7$ trillion: Costs include $\$ 1.24$ trillion in lost productivity, according to study documenting role of obesity and overweight in chronic diseases, 2018. Available: https://www. sciencedaily.com/releases/2018/10/181030163458.htm [Accessed 7 Oct 2020].

15 OECD. The heavy burden of obesity: the economics of prevention. Paris: OECD Publishing, 2019.

16 Shekar M, Popkin B, eds. Obesity: health and economic consequences of an impending global challenge. Washington: World Bank Group, 2019.

17 World Health Organization. Economics of tobacco toolkit: assessment of the economic costs of smoking, 2011. Available: https://apps.who.int/iris/handle/10665/44596 [Accessed 24 Nov 2020].

18 Rice DP. Estimating the cost of illness. Am J Public Health Nations Health 1967;57:424-40.

19 Jo C. Cost-Of-Illness studies: concepts, scopes, and methods. Clin Mol Hepatol 2014;20:327-37.

20 Macchi E. Worth your weight? Experimental evidence on the benefits of obesity in low-income countries, 2020. Available: https:// elisamacchi.github.io/papers/wyw_macchi_draft.pdf [Accessed 7 Dec 2020].

21 GHDx. GBD results tool. Available: http://ghdx.healthdata.org/gbdresults-tool [Accessed 11 Sep 2020].

22 World Health Organization. Global health expenditures database, 2020. Available: http://www.who.int/health-accounts/ghed/en/

23 World Bank. World development indicators. Available: https:// databank. worldbank.org/reports.aspx?source=world-developmentindicators [Accessed 21 Sep 2020].

24 United Nations Population Division. World Population Prospects. Available: https://population.un.org/wpp/ [Accessed 9 Oct 2020].

25 Edwards $\mathrm{CH}$, Aas E, Kinge JM. Body mass index and lifetime healthcare utilization. BMC Health Serv Res 2019;19:696.

26 Campos-Vazquez RM, Gonzalez E. Obesity and hiring discrimination. Econ Hum Biol 2020;37:100850.

27 Dang A, Maitra P, Menon N. Labor market engagement and the body mass index of working adults: evidence from India. Econ Hum Biol 2019;33:58-77

28 Al-Hanawi MK, Keetile M. Socio-Economic and demographic correlates of non-communicable disease risk factors among adults in Saudi Arabia. Front Med 2021;8:605912.

29 Al-Hanawi MK, Chirwa GC, Kamninga TM. Decomposition of gender differences in body mass index in Saudi Arabia using unconditional Quantile regression: analysis of national-level survey data. Int J Environ Res Public Health 2020;17:2330.

30 Palomo L, Félix-Redondo F-J, Lozano-Mera L, et al. Cardiovascular risk factors, lifestyle, and social determinants: a cross-sectional population study. Br J Gen Pract 2014;64:e627-33.

31 Pit SW, Byles J. The association of health and employment in mature women: a longitudinal study. J Womens Health 2012;21:273-80.

32 Langley PC, Tornero Molina J, Margarit Ferri C, et al. The association of pain with labor force participation, absenteeism, and presenteeism in Spain. J Med Econ 2011;14:835-45.

33 Pisa PT, Behanan R, Vorster $\mathrm{HH}$, et al. Social drift of cardiovascular disease risk factors in Africans from the North West Province of South Africa : the PURE study : cardiovascular topics. Cardiovasc J Afr 2012;23:371-8.

34 United Nations Population Division. World population prospects, 2019. Available: https://population.un.org/wpp/Download/Standard/ CSV/ [Accessed 17 Apr 2020].

35 Jamison DT, Summers LH, Alleyne G. Global health 2035: a world converging within a generation - Online supplementary appendix 3 . The Lancet 2013;382:1898-955.

$36 \mathrm{Ng} \mathrm{M}$, Fleming T, Robinson M, et al. Global, regional, and national prevalence of overweight and obesity in children and adults during 1980-2013: a systematic analysis for the global burden of disease study 2013. The Lancet 2014;384:766-81.

37 Foreman KJ, Marquez N, Dolgert A, et al. Forecasting life expectancy, years of life lost, and all-cause and cause-specific mortality for 250 causes of death: reference and alternative 
scenarios for $2016-40$ for 195 countries and territories. The Lancet 2018;392:2052-90.

38 Turner HC, Lauer JA, Tran BX, et al. Adjusting for inflation and currency changes within health economic studies. Value in Health 2019;22:1026-32.

39 WHO. NCD global monitoring framework. Available: http://www.who. int/nmh/global monitoring framework/en/ [Accessed 12 Oct 2020].

40 Bahia L, Coutinho ESF, Barufaldi LA, et al. The costs of overweight and obesity-related diseases in the Brazilian public health system: cross-sectional study. BMC Public Health 2012;12:440.

41 Viscusi WK, Aldy JE. The value of a statistical life: a critical review of market estimates throughout the world. J Risk Uncertain 2003;27:5-76.

42 Popkin BM, Corvalan C, Grummer-Strawn LM. Dynamics of the double burden of malnutrition and the changing nutrition reality. The Lancet 2020;395:65-74.

43 Kilpi F, Webber L, Musaigner A, et al. Alarming predictions for obesity and non-communicable diseases in the middle East. Public Health Nutr 2014;17:1078-86.

44 Webber L, Kilpi F, Marsh T, et al. High rates of obesity and noncommunicable diseases predicted across Latin America. PLoS One 2012;7:e39589.

45 Swinburn BA, Kraak VI, Allender S, et al. The global Syndemic of obesity, undernutrition, and climate change: the Lancet Commission report. The Lancet 2019;393:791-846.

46 World Health Organization. Tackling NCDs: 'Best buys' and other recommended interventions for the prevention and control of noncommunicable diseases. Geneva: World Health Organization, 2017.

47 Nutter S, Russell-Mayhew S, Arthur N, et al. Weight bias as a social justice issue: a call for dialogue. Can Psychol 2018;59:89-99.

48 Kang JH, Jeong BG, Cho YG, et al. Socioeconomic costs of overweight and obesity in Korean adults. J Korean Med Sci 2011;26:1533-40.

49 Australian Bureau of Statistics. Household expenditure survey, Australia: summary of results, 2015-16, 2017. Available: https:// www.abs.gov.au/statistics/economy/finance/household-expendituresurvey-australia-summary-results/latest-release [Accessed 16 Oct 2020].

50 Paiva G, Silva D, Feijo C. Consumption and socioeconomic classification in Brazil: a study based on the Brazilian family expenditure survey 2013.

51 Key indicators of household expenditure on services and durable goods NSS 72nd round (July 2014-June 2015), 2016. Available: https://www.thehinducentre.com/multimedia/archive/02914/Key_ Indicators_of_2914425a.pdf

52 National Institute of Statistics and Geography (INEGI). Encuesta Nacional de Ingresos y Gastos de los Hogares (ENIGH) 2018, 2018. Available: http://en.www.inegi.org.mx/contenidos/programas/enigh/ nc/2018/doc/enigh2018 ns presentacion resultados.pdf

53 General Authority for Statistics (GASTAT). Household income and expenditure survey 2018, 2018. Available: https://www.stats.gov. sa/sites/default/files/household_income_and_expenditure_survey 2018_en_27-6-2019.pdf

54 Lehohla P. Measuring household expenditure on public transport: in-depth analysis of the National household travel survey 2013 data technical report No. 03-20-11, 2015. Available: http://www.statssa. gov.za/publications/Report-03-20-11/Report-03-20-112013.pdf

55 Instituto Nacional de Estadistica (INE). Average spending per household, average spending per person and distribution of spending, survey of family budgets. Available: https://www.ine.es/ jaxiT3/Datos.htm?t=24900\#!tabs-tabla [Accessed 16 Oct 2020].

56 Income-Expenditure Statistics Group, Social Statistics Division, National Statistical Office, Ministry of Digital Economy and Society. The 2017 household socio-economic survey whole Kingdom, 2018. Available: http://www.nso.go.th/sites/2014en/Survey/social/ household/household/2017/whole\%20kingdom/Full\%20Report.pdf

57 Kudel I, Alves JS, de Menezes Goncalves T, et al. The association between body mass index and health and economic outcomes in Brazil. Diabetol Metab Syndr 2018;10:20.

58 Korda RJ, Joshy G, Paige E, et al. The relationship between body mass index and hospitalisation rates, days in hospital and costs: findings from a large prospective linked data study. PLOS One 2015;10:e0118599.

59 Espallardo O, Busutil R, Torres A, et al. The impact of severe obesity on healthcare resource utilisation in Spain. Obes Surg 2017;27:2058-66.

60 NCD-RisC. Data Downloads: Download files containing country risk factor data, 2017. Available: http://ncdrisc.org/data-downloads.html

61 Average annual wages. Available: https://stats.oecd.org/viewhtml. aspx?datasetcode=AV_AN_WAGE\&lang $=e n[$ Accessed 25 Nov 2020].

62 International Labour Office. Global wage report 2018/19: what lies behind gender pay gaps 2018 .

63 International Labour Organization. Mean nominal monthly earnings of employees by sex and economic activity - Harmonized series, Nov. 2019 (5) - Annual; Mean real monthly earnings of employees, annual growth - ILO modelled estimates, Nov. 2019 (5) - Annual, 2020. Available: https://ilostat.ilo.org/data

64 Ordoñez AM, Madalozzo Schieferdecker ME, Cestonaro T, et al. Nutritional status influences the length of stay and clinical outcomes in patients hospitalized in internal medicine wards. Nutr Hosp 2013;28:1313-20.

65 Keramat SA, Alam K, Gow J, et al. Gender differences in the longitudinal association between obesity, and disability with workplace absenteeism in the Australian working population. PLOS One 2020;15:e0233512.

66 Maseko M. Chronic non-communicable diseases (NCDS), absenteeism and workplace wellness initiatives at a consumer goods company in South Africa, 2019. Available: http://etd.uwc.ac. za/xmlui/handle/11394/7636 [Accessed 2 Jul 2021]

67 Catalina-Romero C, Sanchez Chaparro MA, Valdivielso P, et al. Estimating the impact of obesity and metabolic phenotype on sickness absence. results from the ICARIA study. Nutr Metab Cardiovasc Dis 2019;29:383-9.

68 PwC. Weighing the cost of obesity: a case for action, 2015. Available: https://www.pwc.com.au/pdf/weighing-the-cost-ofobesity-final.pdf

69 Hayman S. The relationship between health risk and workplace productivity in Saudi Arabia, 2016. Available: https://www.proquest. com/openview/70186936e3eb78193eaca0f1aaa0b963/1?pqorigsite $=$ gscholar $\& \mathrm{cbl}=18750$ 